\title{
Review
}

\section{Cracking the death code: apoptosis-related histone modifications}

\author{
J Füllgrabe ${ }^{1}$, N Hajji ${ }^{1,2}$ and B Joseph ${ }^{\star, 1}$
}

The degradation and compaction of chromatin are long-standing hallmark features of apoptosis. The histones, chief protein components of chromatin, are subjected to a wide range of post-translational modifications. An increasing body of evidence suggests that combinations of epigenetic histone modifications influence the overall chromatin structure and have clear functional consequences in cellular processes including apoptosis. This review describes the work to date on the posttranslational modification of histones during apoptosis, their regulation by enzymatic complexes and discusses the existence of the apoptotic histone code.

Cell Death and Differentiation (2010) 17, 1238-1243; doi:10.1038/cdd.2010.58; published online 14 May 2010

Histones are the chief protein components of chromatin, acting as spools around which DNA winds, and having a role in gene regulation. ${ }^{1}$ In eukaryotes, an octamer of histones two copies of each of the four core histone proteins H2A, $\mathrm{H} 2 \mathrm{~B}, \mathrm{H} 3$ and $\mathrm{H} 4-$ is wrapped by $147 \mathrm{bp}$ of DNA to form a nucleosome - the fundamental unit of chromatin ${ }^{2}$ (Figure 1a). In addition, histone $\mathrm{H} 1$, located at a position adjacent to the nucleosome core is involved with the packing of the "beads on a string' sub-structures into a higher order structure. In most eukaryotes, histones are expressed as a family of sequence variants encoded by multiple genes. As different histone variants can contribute to a distinct or unique nucleosomal architecture, this heterogeneity can be exploited to regulate a wide range of nuclear functions, and evidence is accumulating that histone variants do indeed have distinct functions. Histones are subjected to a wide variety of post-translational modifications including lysine acetylation, lysine and arginine methylation, serine and threonine phosphorylation and lysine ubiquitination and sumoylation as well as ADP ribosylation, all of which are carried out by histone-modifying enzyme complexes in a dynamic manner (reviewed in Kouzarides and Khorasanizadeh ${ }^{3,4}$ ) (Figure 1b). These modifications occur primarily within the histone amino-terminal tails protruding from the surface of the nucleosome as well as on the globular core region. ${ }^{5}$ Histone modifications function in both long-term (i.e. determinants of chromatin conformation) and in more short-term, ongoing processes (reviewed in Turner ${ }^{6}$ ). For the latter, histone modifications can be considered the endpoints, on chromatin, of cellular signaling pathways and a mechanism through which the genome can respond to environmental stimuli. An increasing body of evidence suggests that these post-translational histone modifications influence the overall chromatin structure and have clear functional consequences. As a result, work on histone modifications and regulation of gene expression have coalesced into the 'histone code' hypothesis, initially proposed by Allis and Turner, that encapsulates the function of histone modifications in chromatin structure and in the regulation of nuclear functions. ${ }^{7,8}$ According to the histone code hypothesis, distinct combinations of histone modifications are related to specific chromatinrelated functions and processes. ${ }^{9}$ As recent evidences indicate, histone modifications have a role in gene transcription, DNA repair, mitosis, meiosis, development and in apoptosis.

Apoptosis, or 'programmed cell death,' is an active process fundamental to the development and homeostasis of multicellular organisms. The activation of a genetically controlled cell death program leading to apoptosis results in characteristic biochemical and morphological features that

\footnotetext{
${ }^{1}$ Department of Oncology Pathology, Cancer Centrum Karolinska, Karolinska Institutet, Stockholm, Sweden

${ }^{*}$ Corresponding author: B Joseph, Department of Oncology Pathology, Cancer Centrum Karolinska, Karolinska Institutet, R8:03, Stockholm 171 76, Sweden.

Tel + 468517738 26; Fax + 46833 9031; E-mail: Bertrand.joseph@ki.se

${ }^{2}$ Current address: Division of Investigative Science, Department of Experimental Medicine and Toxicology, Imperial College London, London, UK.

Keywords: apoptosis; histone modification; epigenetic

Abbreviations: ac, acetylated; ATM, ataxia telangiectasia mutated; BRCA1, breast cancer 1, early onset; Chk2, CHK2 checkpoint homolog (Schizosaccharomyces pombe); DFF40, DNA fragmentation factor 40; DNA-PK, DNA-dependent protein kinase; EYA, mammalian homologue of the Drosophila eyes absent; $\mathrm{H} 2 \mathrm{~A}$, histone 2A; H2B, histone 2B; H3, histone 3; H4, histone 4; HAT, histone acetyltransferase; HDAC, histone deacetylase; HDACl, HDAC inhibitor; HDM, histone demethylase; hMOF, human orthologue of the Drosophila melanogaster males absent on the first gene; HMT, histone methyltransferase; K, lysine; MDC1, mediator of DNA damage checkpoint protein 1; me, methylated; MRE11, meiotic recombination 11 homolog A (Saccharomyces cerevisiae); Mst1, mammalian sterile twenty kinase 1; NBS1, Nijmegen breakage syndrome 1 (nibrin); NF- $\kappa \mathrm{B}$, nuclear factor $\kappa$-light-chain-enhancer of activated B cells; ph, phosphorylated; PKC $\delta$, protein kinase C- $\delta$; R, arginine; RAD50, RAD50 homolog (S. cerevisiae); Ran, ras-related nuclear protein; RanBP1, Ran-specific GTPase-activating protein; RanGAP1, Ran GTPase-activating protein 1; RCC1, regulator of chromosome condensation 1; S, serine; SIRT1, sirtuin 1; T, threonine; ub, ubiquitinylated; WICH complex, WSTF-ISWI ATP-dependent chromatin-remodeling complex; WSTF, Williams-Beuren syndrome transcription factor; 53BP1, p53-binding protein 1

Received 17.2.10; revised 07.4.10; accepted 14.4.10; Edited by G Melino; published online 14.5.10
} 

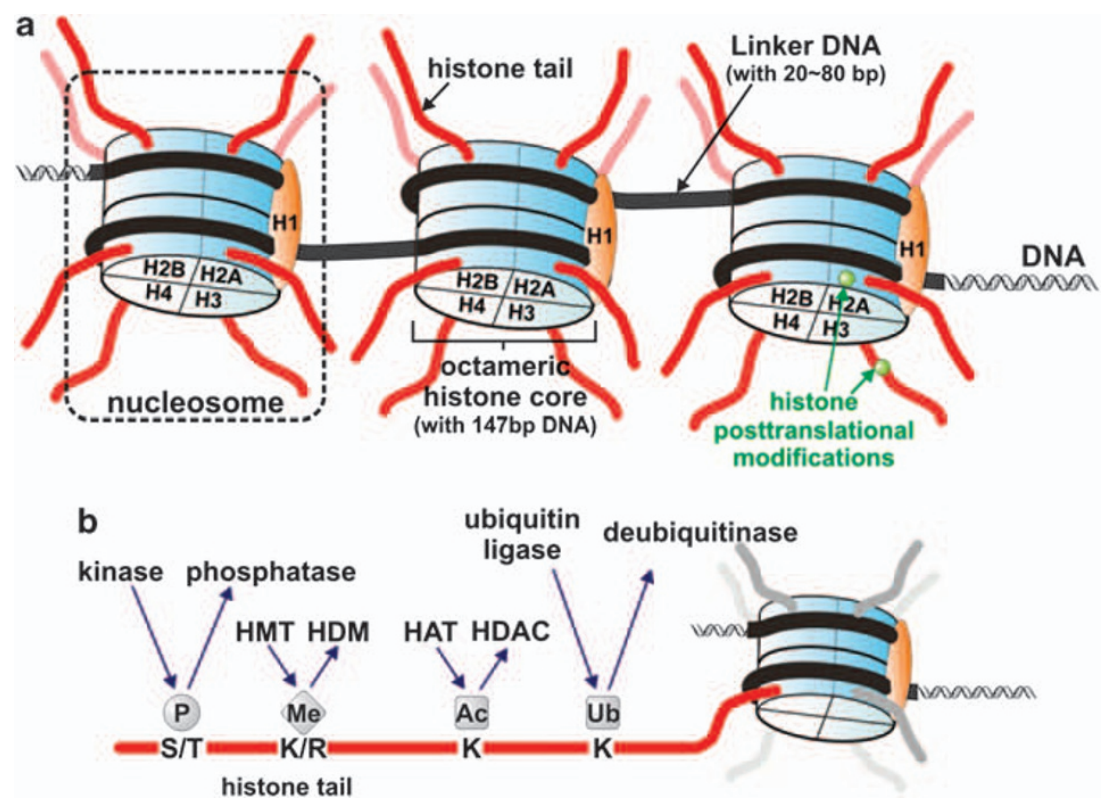

Figure 1 Chromatin structure and histone-modifying enzymes. (a) Chromatin is made of repeating units of nucleosomes, which consist of $\sim 147$ base pairs of DNA wrapped around a histone octamer consisting of two copies of each of the core histones $\mathrm{H} 2 \mathrm{~A}, \mathrm{H} 2 \mathrm{~B}, \mathrm{H} 3$, and $\mathrm{H} 4$. Linker histone $\mathrm{H} 1$ is positioned on top of the nucleosome core particles stabilizing higher order chromatin structure. The histones are subject to a wide variety of post-translational modifications, primarily on their $\mathrm{N}$-terminal tails, but also in their globular core region. (b) The dynamic nature of histone modifications. The modifications that occur on histone tails are shown together with the enzymes that lay down and remove the marks. ac, acetylated; HAT, histone acetyltransferase; HDAC, histone deacetylase; HDM, histone demethylase; HMT, histone methyltransferase; me, methylated; ph, phosphorylated; ub, ubiquitinylated

take place both outside and inside the nucleus. Chromatin condensation paralleled by DNA fragmentation is one of the most important nuclear events occurring during apoptosis. ${ }^{10}$ Owing to the regulated nature of apoptosis, epigenetic features are likely to have a major role in the nuclear changes experienced by apoptotic cells.

Histone modifications, and in particular phosphorylation and acetylation, have long been suggested to affect chromatin function and structure during cell death. A decade ago, Lee et al. ${ }^{11}$ established, using inhibitors of protein phosphatase, that phosphorylation of histones may be involved in thymocyte apoptosis. This observation was later confirmed during astrocyte apoptosis. ${ }^{12}$ Histone acetylation has long been known to maintain the chromatin in an open and accessible conformation to accommodate the transcriptional machinery and to have a major role in regulating gene expression. In a study of the structural changes that occur in chromatin of apoptotic cells, Allera et al. ${ }^{13}$ reported that histones became deacetylated in rat thymocytes that were induced to undergo apoptosis by glucocorticoids. Collectively, these results support the idea that chemical modification of histones is involved in the chromatin alterations in cells undergoing apoptosis. In fact, it has further been shown that phosphorylation of histone $\mathrm{H} 2 \mathrm{~A}, \mathrm{H} 2 \mathrm{~B}, \mathrm{H} 3$ and $\mathrm{H} 4$, dephosphorylation of histone $\mathrm{H} 1$, acetylation of histone $\mathrm{H} 2 \mathrm{~B}, \mathrm{H} 4$, hypoacetylation of histone $\mathrm{H} 4$, methylation of histone $\mathrm{H} 3$ and $\mathrm{H} 4$ and de-ubiquitylation of histone $\mathrm{H} 2 \mathrm{~A}$ are associated with nuclear events of the apoptotic process (Table 1). ${ }^{14}$ In this review, we examine and discuss the different histone protein residues that have been shown to be regulated by post-translational modifications during apoptosis - that is the apoptotic histone mark - and how these marks may affect chromatin function and structure during cell death (Figure 2).

\section{Apoptotic Dephosphorylated Histone H1: the Lost Mark?}

One of the first histone post-translational modifications suggested to be linked to the apoptotic process was the dephosphorylation of histone $\mathrm{H} 1$. Linker histone $\mathrm{H} 1$ is highly phosphorylated in normal growing cells. A correlation between early apoptotic dephosphorylation of histone $\mathrm{H} 1$ and the onset of typical chromatin oligonucleosomal fragmentation has been described..$^{15,16}$ Two lines of evidence point to histone $\mathrm{H} 1$ contribution to internucleosomal chromatin cleavage. First, $\mathrm{H} 1$ histones are associated with the linker DNA, which connects two adjacent nucleosomes and is the site of DNA cleavage during apoptosis. Second, linker histones enhance the activity of DNA fragmentation factor 40 (DFF40/ CAD), the nuclease that cleaves DNA during apoptosis. However, recent investigation revealed that there is no strict correlation between initial apoptotic histone $\mathrm{H} 1$ dephosphorylation and the onset of apoptotic DNA fragmentation. Histone $\mathrm{H} 1$ dephosphorylation is neither a prerequisite for nor an absolute consequence of internucleosomal cleavage. Moreover, the phosphorylation state of $\mathrm{H} 1$ histones does not seem to influence the activation effect of $\mathrm{H} 1$ histones on the activity of DFF40. ${ }^{17}$

\section{Reciprocal Epigenetic Histone Marks of Dying and Non-Dying Cells}

Histone H2B phosphorylation at Serine 14 (H2B-S14ph) has been proposed as an epigenetic marker of apoptotic cells, 
Table 1 Post-translational histone modifications associated with apoptosis

\begin{tabular}{|c|c|c|c|c|}
\hline Histone modifications & & $\begin{array}{l}\text { Enzymes } \\
\text { involved }\end{array}$ & Function and implication for apoptosis & References \\
\hline Phosphorylated H1 & () & Caspase(s) & $\begin{array}{l}\text { Enhances the activity of DFF40/CAD; increases internucleosomal chromatin } \\
\text { cleavage (controversia) }\end{array}$ & 14-17 \\
\hline $\begin{array}{l}\text { Phosphorylated } \mathrm{H} 2 \mathrm{~A} \text {, } \\
\mathrm{H} 2 \mathrm{~B}, \mathrm{H} 3, \mathrm{H} 4\end{array}$ & O & ND & Associated with apoptosis & $11,12,14,48$ \\
\hline Acetylated $\mathrm{H} 4$ & () & ND & $\begin{array}{l}\text { Apoptotic release of hypoacetylated and trimethylated histone } \mathrm{H} 4 \text { and } \\
\text { internucleosomal fragmented hypermethylated DNA originating from perinuclear } \\
\text { heterochromatin }\end{array}$ & 49 \\
\hline Acetylated $\mathrm{H} 2 \mathrm{~B}$ and $\mathrm{H} 4$ & A & ND & Associated with apoptosis & 14,50 \\
\hline Methylated $\mathrm{H} 3$ and $\mathrm{H} 4$ & 1 & ND & $\begin{array}{l}\text { Apoptotic release of hypoacetylated and trimethylated histone } \mathrm{H} 4 \text { and } \\
\text { internucleosomal fragmented hypermethylated DNA originating from perinuclear } \\
\text { heterochromatin }\end{array}$ & 43,49 \\
\hline H2a-ub & () & Caspase(s) & Coincides with the onset of nuclear pyknosis and chromatin condensation & 14,51 \\
\hline H2A.X-S139ph & O & DNA-PK & $\begin{array}{l}\text { Signal for the assembly of apoptotic } \gamma-\mathrm{H} 2 \mathrm{AX} \text { ring, provide docking site for DNA repair } \\
\text { or pro-apoptotic factors }\end{array}$ & 16,27 \\
\hline H2A-Y142ph & $\theta$ & $\begin{array}{l}\text { WICH } \\
\text { complex } \\
\text { EYA-3 }\end{array}$ & $\begin{array}{l}\text { Promotes the recruitment of pro-apoptotic factors to H2A.X-S139ph, inhibits the } \\
\text { recruitment of DNA repair factors to this site } \\
\text { Promotes the recruitment of DNA repair factors to H2A.X-S139ph, induces DNA repair }\end{array}$ & $29-31$ \\
\hline H2B-K12ac & A & ND & Associated with apoptosis & 52 \\
\hline H2B-S14ph & A & $\mathrm{PKC}-\delta$ & $\begin{array}{l}\text { Induced by multiple death triggers, promotes chromatin condensation alt. } \\
\text { internucleosomal DNA fragmentation sequesters RCC } 1 \text { and reduces nuclear import } \\
\text { of pro-survival factors } \\
\text { Acinus-dependent PKC- } \delta \text { activation enhances H2B-S14 phosphorylation, which } \\
\text { correlates with chromatin condensation during apoptosis }\end{array}$ & 18,19 \\
\hline H2B-K15ac & $\boldsymbol{D}$ & $\mathrm{CBP} / \mathrm{p} 300$ & $\begin{array}{l}\text { Property of non-dying cells; loss of this mark is required for the appearance of the } \\
\text { H2B-S14ph apoptotic mark }\end{array}$ & 18,19 \\
\hline H3-K27me & A & ND & Associated with apoptosis in osteosarcoma cells & 47 \\
\hline H3-T45ph & P & $\mathrm{PKC}-\delta$ & Increases DNA accessibility, facilitates DNA fragmentation & 42,43 \\
\hline \multirow[t]{2}{*}{$\mathrm{H} 4-\mathrm{K} 16 \mathrm{ac}$} & (1) & hMOF & Increases chromatin accessibility, promotes DNA damage-induced cell death & $37,40,41,50$ \\
\hline & 1 & SIRT1 & Decreases chromatin accessibility, reduces DNA damage-induced cell death & 40 \\
\hline
\end{tabular}

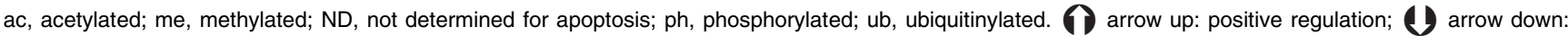
negative regulation.

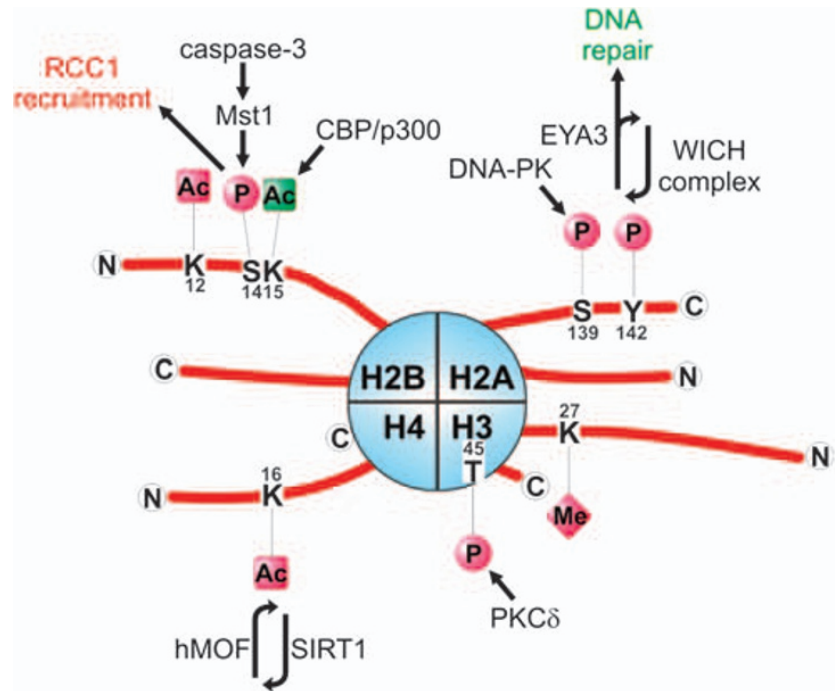

Figure 2 Apoptotic histone code. Specific histone modifications that have been shown to occur in apoptotic cells are shown in red whereas the H2B-K15ac mark, a hallmark of non-dying cells is shown in green. The enzymes reported to carry out these modifications are shown in black. ac, acetylated; me, methylated; ph, phosphorylated; ub, ubiquitinylated

induced by multiple death triggers ${ }^{18,19}$ whereas acetylation at the adjacent Lysine 15 (H2B-K15ac) is a property of non-dying cells. The H2B-S14ph mark, depending on the cell type or the apoptotic agents used to trigger cell death, has been associated either with chromatin condensation ${ }^{19}$ or with internucleosomal DNA fragmentation. ${ }^{20}$ These modifications appear to be reciprocal and deacetylation of $\mathrm{H} 2 \mathrm{~B}-\mathrm{K} 15$ is necessary to allow H2B-S14 phosphorylation. ${ }^{20}$ Phosphorylation of H2B-S14 is catalyzed by mammalian sterile twenty (Mst1) kinase. Mst1 promotes H2B-S14ph in vitro and in vivo, and the onset of H2B-S14 phosphorylation is dependent on cleavage and activation of Mst1 by caspase-3, an aspartatespecific protease and critical executor of apoptosis. ${ }^{19,21}$ Caspase cleavage of Mst1 promotes its nuclear translocation and subsequent chromatin condensation. ${ }^{22}$ A similar mechanism is present in yeast cells. Here, deacetylation of the H2B$\mathrm{K} 11$ histone mark, which is found in growing cells, is necessary to allow the phosphorylation of the apoptotic mark H2B-S10 these are the corresponding residues for H2B-K15 and H2B$\mathrm{S} 16$ in human. ${ }^{23}$ Ste20 kinase, a yeast homolog of mammalian Mst1 kinase, also translocates into the nucleus but in a caspase-independent manner and directly phophorylates $\mathrm{H} 2 \mathrm{~B}$ at Serine $10 .^{24}$ The conservation of this $\mathrm{H} 2 \mathrm{~B}$ histone mark and the enzyme system controlling its phosphorylation from yeast to human points to an ancient mechanism likely to regulate cell death in a wide range of organisms.

It is worth noting that, the regulator of chromosome condensation 1 (RCC1) protein, a guanine nucleotide exchange factor, reads the $\mathrm{H} 2 \mathrm{~B}-\mathrm{S} 14 \mathrm{ph}$ histone mark created by caspase-activated Mst1, in turn reducing $\mathrm{RCC} 1$ mobility in 
the presence of $\mathrm{H} 2 \mathrm{~B}-\mathrm{S} 14 \mathrm{ph}$. RCC1 normally catalyzes the formation of RanGTP in the nucleus, whereas hydrolysis of RanGTP is stimulated by RanGAP1 and RanBP1 in the cytoplasm. Its immobilization on chromosomes reduces the level of RanGTP in the nucleus, which in turn leads to the inactivation of the nuclear transport machinery. As a consequence, nuclear localization signal-containing proteins, including survival factors such as NF- $\kappa \mathrm{B}-\mathrm{p} 65$, remain bound to importins $\alpha$ and $\beta$ in the cytoplasm. ${ }^{25}$ Therefore, the H2B-S14ph histone modification is not simply a hallmark of apoptosis but also seems to directly contribute to the inactivation of survival pathways including NF- $\kappa \mathrm{B}$.

\section{DNA Repair/Survival or Cell Death: the Histone sWltCH}

Phosphorylation on Serine 139 of the histone variant H2A.X (H2A.X-S139ph; also called gamma-H2A.X ( $\gamma-H 2 A . X)$ ), in response to DNA damage is the major signal for the assembly of the $\gamma-\mathrm{H} 2 \mathrm{~A}$.X chromatin domain, a region surrounding an unrepaired DNA double-strand break, that is characterized by the accumulation of a large number of DNA damage response proteins. ${ }^{26}$ However, $\gamma$-H2A.X, a hallmark of DNA damage response, also forms early during apoptosis induced by death receptors agonists and stimuli targeting the intrinsic apoptotic pathway. ${ }^{16,27,28} \gamma$-H2A.X is initiated in the nuclear periphery immediately adjacent to the nuclear envelope whereas total H2A.X remains distributed throughout the nucleus. This process is referred to as the ' $\gamma-\mathrm{H} 2 \mathrm{~A}$.X ring'. ${ }^{27,28}$ The $\gamma-\mathrm{H} 2 \mathrm{AX}$ ring contains the activated checkpoints kinases, ATM, Chk2 and DNA-PK; the last being the main effector for apoptotic $\gamma-\mathrm{H} 2 \mathrm{AX}$ phosphorylation. Notably, the $\gamma-\mathrm{H} 2 \mathrm{AX}$ ring formation not only coincides with H2A.X-S139ph but also with the apoptosis-associated histone modification H2B-S14ph. ${ }^{28}$

Although the regulatory mechanisms and signaling pathways controlling DNA repair and apoptosis are well characterized, the precise molecular strategies that determine the ultimate choice of DNA repair/survival or apoptotic cell death remain incompletely understood. The recent discovery of H2A.X Tyrosine 142 phosphorylation (H2A.X-Y142ph) by the WSTF-ISWI ATP-dependent chromatin-remodeling complex (WICH) and its dephosphorylation by the EYA phosphatases (mammalian homologue of the Drosophila eyes absent), and in particular EYA3, may provide substantial novel insight into this process. ${ }^{29-32}$ Williams-Beuren syndrome transcription factor (WSTF), a subunit of the WICH complex, bears a novel kinase domain at its $\mathrm{N}$-terminus that constitutively targets H2A.X-Y142ph. ${ }^{29}$ This single histone modification appears to determine the relative recruitment of either DNA repair or proapoptotic factors to $\gamma-\mathrm{H} 2 \mathrm{AX}$ sites of DNA damage and functions as an active determinant of repair/survival versus apoptotic responses to DNA damage.$^{30}$ In the presence of H2A.X-Y142ph, binding of repair factors (MRE11, RAD50, NBS1, 53BP1 and BRCA1) to H2A.X-S139ph, which is mediated by mediator of DNA damage checkpoint protein 1 (MDC1), is inhibited, whereas recruitment of pro-apoptotic factors such as the stress-response kinase JNK1 is promoted. ${ }^{33,34}$ The simultaneous presence of Y142ph and S139ph marks results in the direct binding of the PTB domain factor Fe65, which mediates the effective recruitment of JNK1. ${ }^{30}$ Thus, the balance of H2A.X-Y142ph phosphorylation/ dephosphorylation may constitute a novel switch mechanism to determine cell fate after DNA damage. ${ }^{29,34}$

\section{Histone Modifications Increase Chromatin Accessibility and DNA Fragmentation}

Histone post-translational modifications have the potential to directly modulate nucleosome structure and consequently DNA accessibility. Indeed, the acetylation state of lysine residues regulates both the local chromatin dynamics as well as higher order chromatin structure. ${ }^{35}$ Acetylation of histone $\mathrm{H} 4$ on Lysine 16 (H4-K16ac) is a prevalent and reversible post-translational chromatin modification in eukaryotes. ${ }^{36,37}$ This single histone modification both disrupts formation of higher order chromatin structure and changes the functional interaction of chromatin-associated proteins, thereby increasing chromatin accessibility. ${ }^{37}$ It is worth noting that loss of $\mathrm{H} 4-\mathrm{K} 16 \mathrm{ac}$ is a common feature of a number of cancers. ${ }^{38}$ Histone deacetylases (HDAC) and histone acetyltransferases control the acetylation state of lysine residues, including those situated in the N-terminal 'tails' of histones. HDAC inhibitors (HDACls) comprise a diverse range of unrelated compounds that all induce an accumulation of hyperacetylated histones resulting in various biological effects, including cell death. ${ }^{39-41}$ Various inhibitors of HDAC activity can sensitize drugresistant cancer cells to DNA-damaging agents. ${ }^{41}$ However, the mechanisms underlying the effects of HDACls remain poorly understood. A recent study revealed that the effect of HDACls is associated with increased acetylation of certain lysines on histones $\mathrm{H} 3$ and $\mathrm{H} 4$, including H4-K16ac. ${ }^{40}$ Overexpression of the histone acetyltransferase human orthologue of the Drosophila melanogaster MOF (males absent on the first) gene (hMOF), known to specifically target $\mathrm{H} 4 \mathrm{~K} 16$, was sufficient to mimic $\mathrm{HDACl}$ sensitization and H4K16 acetylation, and importantly, knock down of hMOF abolished the HDACl-mediated sensitizing effects as well as the increase in H4K16 acetylation. Conversely, knock down of the H4K16 deacetylase SIRT1 mimicked HDACl treatment whereas overexpression of SIRT1 abolished H4K16 acetylation and significantly reduced the sensitizing effects of HDACls. ${ }^{40}$ Thus, the opposing effects of hMOF and SIRT1 regulate $\mathrm{H} 4 \mathrm{~K} 16$ acetylation showing that this histone mark controls the sensitivity of cancer cells to DNA damageinduced cell death. ${ }^{40}$

Another apoptotic epigenetic histone mark, which has been proposed to be linked to increased DNA accessibility, is phosphorylation of Threonine 45 within the histone core of histone H3 (H3-T45ph). H3-T45ph increases dramatically in apoptotic cells, around the time of DNA nicking. Protein kinase $\mathrm{C}-\delta(\mathrm{PKC} \delta)$, which itself becomes highly active after caspase3 cleavage, was identified as the agent responsible for $\mathrm{H3}$ T45 phosphorylation. ${ }^{42}$ H3-T45 has been shown to have an important role in nucleosome structure. ${ }^{43}$ Therefore, given the fact that H3-T45 occupies a structurally interesting position within the nucleosome, it was postulated that phosphorylation of $\mathrm{H} 3 \mathrm{~T} 45$ by $\mathrm{PKC} \delta$ during late apoptosis induces structural change within the nucleosome to facilitate DNA fragmentation. ${ }^{42}$ Interestingly, it should be mentioned that in budding yeast H3-T45ph has rather been linked to DNA replication and its absence with replicative defects. In addition, no 
discernable increase in H3-T45 phosphorylation levels is observed during cell death, indicating that $\mathrm{H} 3-\mathrm{T} 45 \mathrm{ph}$ probably does not function in the apoptotic pathway in yeast. ${ }^{44}$

Finally, phosphorylation of residue serine 10 on histone H3 (H3-S10ph) is associated with two apparently opposed chromatin states, namely the highly condensed mitotic chromosomes and the relaxed chromatin of certain activated genes during interphase (reviewed in Prigent and Dimitrov ${ }^{45}$ ). H3-S10 phosphorylation also occurs when cells are exposed to various death stimuli suggesting its possible implication in the control of cell survival. ${ }^{46}$ However, the actual cellular effects of H3-S10 phosphorylation remain enigmatic and it is not yet clear whether H3-S10ph contributes to the apoptotic program.

\section{Perspectives}

The 'histone code' hypothesis was proposed as a generalization of the discovery that combinations of covalent posttranslational modifications of histones influence chromatin structure and lead to varied transcriptional outputs. ${ }^{7}$ Considering the long known influence of histone modifications on the compaction of chromatin, it is reasonable that the chromatin compaction as well as DNA fragmentation occurring during apoptosis would need the modification of histone marks. The direct links, uncovered in several recent publications, between apoptosis and histone modifications make it unlikely that they are just a 'useless' feature of apoptosis. Similar to the 'death code' in informatics, a whole palette of histone modifications seem to occur during apoptosis, creating an epigenetic code, which decides on the destiny of the cell. In fact, several histone modifications have been firmly linked to apoptosis-induced chromatin changes, providing collective evidence for an 'apoptotic histone code' (Figure 1).

Notably, caspases, a family of cysteine proteases, which have an essential role in the execution of apoptosis, control histone-modifying enzymes and promote histone posttranslational modifications (i.e. H2A de-ubiquitylation, H2BS14 and H3-T45 phosporylation). In addition, the presence or absence of specific epigenetic histone marks occurring during apoptotic cell death appear to work as binding platforms for the recruitment of protein complexes regulating cell life and death decisions. For example, H2B-S14 phosphorylation contributes to the inactivation of survival pathways by immobilizing the nucleotide exchange factor RCC1 and consequently the nuclear import of pro-survival factors. H2A.X-Y142ph, in concert with H2A.X-S139ph/ $\gamma$ H2A.X, also acts as a binding site for proteins, contributing to the decision between DNA repair and survival or cell death. In the presence of H2A.X-Y142ph, recruitment of repair factors to H2A.X-S139ph is inhibited whereas recruitment of pro-apoptotic factors is promoted. Finally, several histone modifications correlate with the occurrence of apoptotic-related chromatin alterations; increased chromatin accessibility (H3-T45ph, H4-K16ac), internucleosomal DNA fragmentation (dephosphorylation $\mathrm{H1}$, H2B-S14ph) and chromatin condensation (H2a de-ubiquitinylation, H2B-S14ph). Thus, the balance between different histone marks may constitute a code that determines cell fate. However, it should be mentioned that a block of apoptosis was not always reported when the described histone modifications were absent. There are also contradictory reports in the literature regarding the functional consequences for loss of histone mark. For example, whereas downregulation of Mst-1, which results in reduction of $\mathrm{H} 2 \mathrm{~B}-\mathrm{S} 14 \mathrm{ph}$ level, was reported to suppress apoptosis, $^{25}$ the combinatory treatment of $\mathrm{HDACl}$ and glucocorticoid, repressing $\mathrm{H} 2 \mathrm{~B}-\mathrm{S} 14$ phosphorylation and internucleosomal DNA degradation, did not prevent apoptosis in thymocytes. ${ }^{20}$ Thus, whether each of the histone marks reviewed participates in the death process per se or is only necessary for the disposal of the DNA still awaits additional investigations.

In addition, further work remains to be done to better establish the sequence of codes (i.e. combinations of histone modifications, timeline of events and interplay of modifications) within the death code regulating the different nuclear apoptotic steps. For example, how H4-K16ac-mediated chromatin decondensation and the resulting increase in sensitivity to death triggers such as DNA damage can be linked to the H2B-S14ph and other epigenetic marks that are associated with apoptotic chromatin condensation and fragmentation.

The role of most apoptotic histone marks in diseases remains to be discovered. It is well known that in cancer the epigenomic landscape undergoes extensive distortion compared to normal cells. The loss of H4-K16ac has already been described for several cancer types and shown to influence cancer cell sensitivity to chemotherapy. ${ }^{38,41}$ Another example is the increased H3-K27 methylation, associated with apoptosis in osteosarcoma cells, ${ }^{47}$ which is also associated with aberrant gene silencing in various forms of cancer and reprogramming of the epigenome during development. Considering the influence of other marks, such as H2B$\mathrm{S} 14 \mathrm{ph}$ on cell death, more deregulation of histone modifications in disease could be imagined. In summary, these unique histone modifications occurring during the course of cell death already provide new features to monitor and study apoptosis.

\section{Conflict of interest}

The authors declare no conflict of interest.

Acknowledgements. We apologize to authors whose primary references could not be cited owing to space limitations. We are thankful to Dr. Edel Kavanagh for helpful discussions. JF is supported by a fellowship from Karolinska Institutet Foundations (KID medel). This work was supported by the Swedish Cancer Society, the Swedish Research Council, and the Karolinska Institutet Foundations (KI Cancer) (BJ).

\section{Note added in proof}

For a computer, the 'death code' defines a routine whose job is to set everything in the computer - registers, memory, flags to zero, including that portion of memory where it is running; its last act is to stomp on its own 'store zero' instruction.

1. Luger K, Mader AW, Richmond RK, Sargent DF, Richmond TJ. Crystal structure of the nucleosome core particle at 2.8 A resolution. Nature 1997; 389: 251-260.

2. Kornberg RD, Lorch Y. Twenty-five years of the nucleosome, fundamental particle of the eukaryote chromosome. Cell 1999; 98: 285-294.

3. Kouzarides T. Chromatin modifications and their function. Cell 2007; 128: 693-705.

4. Khorasanizadeh $\mathrm{S}$. The nucleosome: from genomic organization to genomic regulation Cell 2004; 116: 259-272. 
5. Cosgrove MS, Boeke JD, Wolberger $\mathrm{C}$. Regulated nucleosome mobility and the histone code. Nat Struct Mol Biol 2004; 11: 1037-1043.

6. Turner BM. Defining an epigenetic code. Nat Cell Biol 2007; 9: 2-6.

7. Strahl BD, Allis CD. The language of covalent histone modifications. Nature 2000; 403 $41-45$.

8. Turner BM. Histone acetylation and an epigenetic code. Bioessays 2000; 22: 836-845.

9. Jenuwein T, Allis CD. Translating the histone code. Science 2001; 293: 1074-1080.

10. Wyllie AH. Glucocorticoid-induced thymocyte apoptosis is associated with endogenous endonuclease activation. Nature 1980; 284: 555-556.

11. Lee E, Nakatsuma A, Hiraoka R, Ishikawa E, Enomoto R, Yamauchi A. Involvemen of histone phosphorylation in thymocyte apoptosis by protein phosphatase inhibitors. IUBMB Life 1999; 48: 79-83.

12. Enomoto R, Tatsuoka H, Komai T, Sugahara C, Takemura K, Yamauchi A et al. Involvement of histone phosphorylation in apoptosis of human astrocytes after exposure to saline solution. Neurochem Int 2004; 44: 459-467.

13. Allera C, Lazzarini G, Patrone E, Alberti I, Barboro P, Sanna P et al. The condensation of chromatin in apoptotic thymocytes shows a specific structural change. J Biol Chem 1997; 272: 10817-10822.

14. Th'ng JP. Histone modifications and apoptosis: cause or consequence? Biochem Cell Biol 2001; 79: 305-311.

15. Kratzmeier M, Albig W, Hanecke K, Doenecke D. Rapid dephosphorylation of H1 histones after apoptosis induction. J Biol Chem 2000; 275: 30478-30486.

16. Talasz H, Helliger W, Sarg B, Debbage PL, Puschendorf B, Lindner H. Hyperphosphorylation of histone H2A.X and dephosphorylation of histone $\mathrm{H} 1$ subtypes in the course of apoptosis. Cell Death Differ 2002; 9: 27-39.

17. Goebel W, Obermeyer N, Bleicher N, Kratzmeier M, Eibl HJ, Doenecke D et al. Apoptotic DNA fragmentation is not related to the phosphorylation state of histone $\mathrm{H} 1$. Biol Chem 2007; 388: 197-206

18. Ajiro K. Histone H2B phosphorylation in mammalian apoptotic cells. An association with DNA fragmentation. J Biol Chem 2000; 275: 439-443.

19. Cheung WL, Ajiro K, Samejima K, Kloc M, Cheung P, Mizzen CA et al. Apoptotic phosphorylation of histone $\mathrm{H} 2 \mathrm{~B}$ is mediated by mammalian sterile twenty kinase. Cell 2003; 113: $507-517$.

20. Ajiro K, Scoltock AB, Smith LK, Ashasima M, Cidlowski JA. Reciprocal epigenetic modification of histone $\mathrm{H} 2 \mathrm{~B}$ occurs in chromatin during apoptosis in vitro and in vivo. Cell Death Differ 2010; e-pub ahead of print 8 January 2010.

21. Graves JD, Gotoh Y, Draves KE, Ambrose D, Han DK, Wright M et al. Caspase-mediated activation and induction of apoptosis by the mammalian Ste20-like kinase Mst1. EMBO J 1998; 17: 2224-2234.

22. Ura S, Masuyama N, Graves JD, Gotoh Y. Caspase cleavage of MST1 promotes nuclear translocation and chromatin condensation. Proc Natl Acad Sci USA 2001; 98 10148-10153.

23. Ahn $\mathrm{SH}$, Diaz RL, Grunstein M, Allis CD. Histone H2B deacetylation at lysine 11 is required for yeast apoptosis induced by phosphorylation of H2B at serine 10. Mol Cell 2006; 24: 211-220.

24. Ahn SH, Cheung WL, Hsu JY, Diaz RL, Smith MM, Allis CD. Sterile 20 kinase phosphorylates histone $\mathrm{H} 2 \mathrm{~B}$ at serine 10 during hydrogen peroxide-induced apoptosis in S. cerevisiae. Cell 2005; 120: 25-36.

25. Wong $\mathrm{CH}$, Chan H, Ho CY, Lai SK, Chan KS, Koh CG et al. Apoptotic histone modification inhibits nuclear transport by regulating RCC1. Nat Cell Biol 2009; 11: 36-45.

26. Fernandez-Capetillo $\mathrm{O}$, Allis $\mathrm{CD}$, Nussenzweig A. Phosphorylation of histone $\mathrm{H} 2 \mathrm{~B}$ at DNA double-strand breaks. J Exp Med 2004; 199: 1671-1677.

27. Solier S, Pommier Y. The apoptotic ring: a novel entity with phosphorylated histones $\mathrm{H} 2 \mathrm{AX}$ and H2B and activated DNA damage response kinases. Cell Cycle 2009; 8: 1853-1859.

28. Solier S, Sordet O, Kohn KW, Pommier Y. Death receptor-induced activation of the Chk2and histone H2AX-associated DNA damage response pathways. Mol Cell Biol 2009; 29 . $68-82$

29. Xiao A, Li H, Shechter D, Ahn SH, Fabrizio LA, Erdjument-Bromage $\mathrm{H}$ et al. WSTF regulates the H2A.X DNA damage response via a novel tyrosine kinase activity. Nature 2009; 457: 57-62

30. Cook PJ, Ju BG, Telese F, Wang X, Glass CK, Rosenfeld MG. Tyrosine dephosphorylation of H2AX modulates apoptosis and survival decisions. Nature 2009; 458: 591-596.
31. Tootle TL, Silver SJ, Davies EL, Newman V, Latek RR, Mills IA et al. The transcription factor Eyes absent is a protein tyrosine phosphatase. Nature 2003; 426: 299-302.

32. Krishnan N, Jeong DG, Jung SK, Ryu SE, Xiao A, Allis CD et al. Dephosphorylation of the C-terminal tyrosyl residue of the DNA damage-related histone H2A.X is mediated by the protein phosphatase eyes absent. J Biol Chem 2009; 284: 16066-16070.

33. Stucki M, Clapperton JA, Mohammad D, Yaffe MB, Smerdon SJ, Jackson SP. MDC1 directly binds phosphorylated histone $\mathrm{H} 2 \mathrm{AX}$ to regulate cellular responses to DNA doublestrand breaks. Cell 2005; 123: 1213-1226.

34. Stucki M. Histone H2A.X Tyr142 phosphorylation: a novel sWltCH for apoptosis? DNA Repair (Amst) 2009; 8: 873-876.

35. Schneider R, Grosschedl R. Dynamics and interplay of nuclear architecture, genome organization, and gene expression. Genes Dev 2007; 21: 3027-3043.

36. Shogren-Knaak M, Peterson CL. Switching on chromatin: mechanistic role of histone H4-K16 acetylation. Cell Cycle 2006; 5: 1361-1365.

37. Shogren-Knaak M, Ishii H, Sun JM, Pazin MJ, Davie JR, Peterson CL. Histone H4-K16 acetylation controls chromatin structure and protein interactions. Science 2006; 311: 844-847.

38. Fraga MF, Ballestar E, Villar-Garea A, Boix-Chornet M, Espada J, Schotta G et al. Loss of acetylation at Lys 16 and trimethylation at Lys20 of histone $\mathrm{H} 4$ is a common hallmark of human cancer. Nat Genet 2005; 37: 391-400.

39. Minucci S, Pelicci PG. Histone deacetylase inhibitors and the promise of epigenetic (and more) treatments for cancer. Nat Rev Cancer 2006; 6: 38-51.

40. Hajij N, Wallenborg K, Vlachos P, Fullgrabe J, Hermanson O, Joseph B. Opposing effects of hMOF and SIRT1 on H4K16 acetylation and the sensitivity to the topoisomerase II inhibitor etoposide. Oncogene 2010; 29: 2192-2204.

41. Haiji N, Wallenborg K, Vlachos P, Nyman U, Hermanson O, Joseph B. Combinatorial action of the HDAC inhibitor trichostatin A and etoposide induces caspase-mediated AlF-dependent apoptotic cell death in non-small cell lung carcinoma cells. Oncogene 2008; 27: 3134-3144.

42. Hurd PJ, Bannister AJ, Halls K, Dawson MA, Vermeulen M, Olsen JV et al. Phosphorylation of histone H3 Thr-45 is linked to apoptosis. J Biol Chem 2009; 284: 16575-16583.

43. Ferreira $\mathrm{H}$, Somers J, Webster R, Flaus A, Owen-Hughes $\mathrm{T}$. Histone tails and the $\mathrm{H} 3$ alphaN helix regulate nucleosome mobility and stability. Mol Cell Biol 2007; 27: 4037-4048.

44. Baker SP, Phillips J, Anderson S, Qiu Q, Shabanowitz J, Smith MM et al. Histone H3 Thr 45 phosphorylation is a replication-associated post-translational modification in S. cerevisiae. Nat Cell Biol 2010; 12: 294-298.

45. Prigent C, Dimitrov S. Phosphorylation of serine 10 in histone H3, what for? J Cell Sci 2003; 116: 3677-3685.

46. Bode AM, Dong Z. Inducible covalent posttranslational modification of histone H3. Sci STKE 2005; 2005: re4

47. Cheng MF, Lee $\mathrm{CH}$, Hsia KT, Huang GS, Lee HS. Methylation of histone H3 lysine 27 associated with apoptosis in osteosarcoma cells induced by staurosporine. Histol Histopathol 2009; 24: 1105-1111.

48. Song C, Kanthasamy A, Anantharam V, Sun F, Kanthasamy AG. Environmental Neurotoxic pesticide increases histone acetylation to promote apoptosis in dopaminergic Neuronal cells: relevance to epigenetic mechanisms of Neurodegeneration. Mol Pharmacol 2010; 77: 621-632.

49. Boix-Chornet M, Fraga MF, Villar-Garea A, Caballero R, Espada J, Nunez A et al. Release of hypoacetylated and trimethylated histone $\mathrm{H} 4$ is an epigenetic marker of early apoptosis. J Biol Chem 2006; 281: 13540-13547.

50. Dieker JW, Fransen JH, van Bavel CC, Briand JP, Jacobs CW, Muller S et al. Apoptosisinduced acetylation of histones is pathogenic in systemic lupus erythematosus. Arthritis Rheum 2007; 56: 1921-1933.

51. Mimnaugh EG, Kayastha G, McGovern NB, Hwang SG, Marcu MG, Trepel J et al. Caspase-dependent deubiquitination of monoubiquitinated nucleosomal histone $\mathrm{H} 2 \mathrm{~A}$ induced by diverse apoptogenic stimuli. Cell Death Differ 2001; 8: 1182-1196.

52. van Bavel CC, Dieker J, Muller S, Briand JP, Monestier M, Berden JH et al. Apoptosisassociated acetylation on histone $\mathrm{H} 2 \mathrm{~B}$ is an epitope for lupus autoantibodies. Mol Immunol 2009; 47: 511-516.

53. Hu Y, Liu Z, Yang SJ, Ye K. Acinus-provoked protein kinase $\mathrm{C}$ delta isoform activation is essential for apoptotic chromatin condensation. Cell Death Differ 2007; 14: 2035-2046. 